\title{
El rastreo selectivo de la diabetes gestacional parece ser adecuado
}

Naylor C, Sermer M, Chen E, et al para el Toronto Trihospital Gestational Diabetes Project Investigators. Selective screening for gestational diabetes mellitus. N Engl J Med 1997;337:1591-96.

\section{Objetivo}

El rastreo de la diabetes mellitus gestacional (DMG) con P50 (prueba de tolerancia oral de $50 \mathrm{~g}$ de glucosa) es frecuentemente indicado a las embarazadas en la semana 24-28 de gestación. El objetivo del estudio es demostrar que el rastreo puede ser optimizado, tomando en cuenta el riesgo de cada embarazada de desarrollar DMG.

\section{Diseño}

Análisis secundario de una cohorte prospectiva de mujeres embarazadas. Diseño y validación de una regla de predicción clínica.

Lugar

Tres hospitales de Toronto, Canadá

\section{Pacientes}

Se analizaron 3152 pacientes. La población fue dividida en dos grupos al azar: 1560 pacientes para desarrollar la regla de predicción y 1571 para validarla. Se incluyeron pacientes $>24$ años que cursaban un embarazo < 24 semanas, sin antecedentes de diabetes meLlitus (DBT). Se excluyeron a mujeres cuyos bebes nacieron antes de la semana 28. Todas las pacientes del estudio habían realizado P50 y el $90 \%$ la CTOG (carga de tolerancia oral). Se obtuvieron datos para completar el análisis de 3131 pacientes (99.3\%).

\section{Evaluación de los factores pronósticos:}

Se evaluaron: edad, raza, índice de masa corporal (IMC), paridad, historia familiar de DBT e historia obstétrica adversa (antecedentes de DMG, anormalidades fetales, macrosomías y muerte fetal sin explicación).

\section{Desarrollo del puntaje clínico}

Para la construcción del puntaje se utilizó la información de la mitad de los participantes. Se identificaron los factores de riesgo independientes para el desarrollo de DMG o intolerancia a la glucosa y se les asignó un valor determinado de acuerdo a la menor o mayor asociación con este resultado. Esta regla fue luego validada en la otra mitad de la muestra. TABLA 1

\begin{tabular}{clc}
\hline & Factor de riesgo & Puntaje \\
\hline Edad & 30 & 0 \\
\hline IMC $^{1}$ & $31-34$ años & 1 \\
\hline & $>34$ & 2 \\
\hline Raza Blanca & 222 & 0 \\
\hline Negra & $22.1-25$ & 2 \\
\hline Asiática & 25 & 3 \\
\hline Otra 2 & & 0 \\
\hline
\end{tabular}

1. Indice de Masa Corporal: peso en $\mathrm{Kg} /$ altura en $\mathrm{m}^{2}$

2. Definieron como otras a: hispánicas, asiáticas del sur (indias, pakistaníes) y de los países del medio Oriente
Desarrollo y validación de nuevas estrategias se rastreo

Se evaluaron distintas estrategias de rastreo según el riesgo de DMG: no rastreo en el grupo de bajo riesgo (score 0-1), rastreo habitual con P50 en grupo de riesgo intermedio (score 2-3) y rastreo utilizando menores umbrales de la P50 en el grupo de alto riesgo (score >3). (Ver tabla 2).

\section{Resultados}

TABLA 2:Porcentajes de detección y de falsos positivos con el rastreo usual y con el rastreo selectivo

\begin{tabular}{|c|c|c|c|c|c|c|}
\hline Estrategia & $\begin{array}{l}\text { Detección } \\
\%(n)\end{array}$ & $\begin{array}{l}\text { Diferencia } \\
\text { Absoluta } \\
\%\end{array}$ & $\begin{array}{l}\text { Valor } \\
\text { dep }\end{array}$ & $\begin{array}{l}\text { Falsos } \\
\text { Positivos } \\
\%(n)\end{array}$ & $\begin{array}{l}\text { Diferencia } \\
\text { Absoluta } \\
\%\end{array}$ & $\begin{array}{l}\text { Valor } \\
\text { de } p\end{array}$ \\
\hline $\begin{array}{l}\text { Rastreo Usual (P50 a todas) } \\
\text { Valor de Corte (VC): } \\
140 \mathrm{mg} / \text { dl a la hora. }\end{array}$ & $78.3(54)$ & & & $17.9(269)$ & & \\
\hline \multicolumn{7}{|l|}{$\begin{array}{l}\text { Rastreo Selectivo } \\
\text { ( } 65 \% \text { de pacientes) }\end{array}$} \\
\hline $\begin{array}{l}\text { Estrategia A: No rastreo a } \\
\text { bajo riesgo, VC P50 score } \\
2-3 \text { de } 140 \mathrm{mg} / \mathrm{dl} \text { y de } \\
128 \mathrm{mg} / \mathrm{dl} \text { para score }>3\end{array}$ & $82.6(57)$ & +4.3 & 0.26 & $16(240)$ & -1.9 & 0.02 \\
\hline $\begin{array}{l}\text { Estrategia B: No rastreo } \\
\text { a bajo riesgo, VC P50 score } \\
2-3 \text { de } 140 \mathrm{mg} / \mathrm{dl} \text { y de } \\
130 \mathrm{mg} / \mathrm{dl} \text { para score }>3\end{array}$ & $81.2(56)$ & +2.9 & 0.41 & $15.4(231)$ & -2.5 & 0.001 \\
\hline $\begin{array}{l}\text { Estrategia C: No rastreo a } \\
\text { bajo riesgo, Valor post- } \\
\text { prandial \# para score } 2-3 \\
\text { y de } 128 \mathrm{mg} / \text { dl para score }>3\end{array}$ & $79.7(55)$ & +1.4 & 0.74 & $13.6(205)$ & -4.2 & 0.001 \\
\hline $\begin{array}{l}\text { Estrategia D: No rastreo a } \\
\text { bajo riesgo, Valor post- } \\
\text { prandial \# para score } 2-3 \\
\text { y de } 130 \mathrm{mg} / \mathrm{dl} \text { para score }>3\end{array}$ & $78.3(54)$ & 0 & 1 & $13(196)$ & -4.9 & 0.001 \\
\hline
\end{tabular}

\# Valor post-prandial: En vez de realizar una P50, se tomó como valores de corte de la glucemia a 148,142 0150 según si la última comida de la embarazada había sido hace menos de 2 horas, hace 2 a 3 hs o hace más de 3 hs, respectivamente (se basan en un estudio previo para demostrar su efectividad similar)

No rastrear al grupo de bajo riesgo (menos de 34 años, con IMC menor o igual a 22, de raza blanca), evitaría la P50 en un 34.7\% (IC 95\% 32.337) de las pacientes. Las estrategias A y B, demostraron tener una tasa de detección similar pero con una reducción pequeña pero significativa de los falsos positivos, en comparación con el rastreo habitual. Por otro lado, las estrategias C y D tuvieron una tasa similar de detección, pero redujeron en forma mayor la tasa de falsos positivos.

\section{Conclusiones}

Un puntaje basado en las características clínicas de las pacientes, permite diseñar estrategias selectivas de rastreo de DMG.

\section{COMENTARIO}

Este estudio forma parte de una serie de trabajos realizados en Toronto sobre la DMG. Aquí los autores toman los datos recolectados para un estudio anterior y diseñan nuevas estrategias de rastreo de la DMG. Es de hacer notar que la incidencia de DMG en esta población fue baja (3.5\%) limitando el poder del estudio para detectar los factores de riesgo de esta patología. Por este motivo los autores decidieron combinar la incidencia de DMG con la de intolerancia gestacional a la glucosa $(10 \%)$, en pos de obtener un mejor poder.

Actualmente tanto la fuerza de tareas Canadiense como la Norteamericana están de acuerdo en que para el rastreo de DMG existe insuficiente evidencia (recomendación tipo $\left.C^{*}\right)^{1}$. El rastreo lo recomienda solamente la American Diabetes Association a través de la prueba de desafío con 50 grs. de glucosa (P50), realizando a las que presentan una glucemia de más de 140 a la hora, una CTOG. Este estudio abre una línea de investigación para poder discriminar qué pacientes se benefician con el rastreo, ya que éste es caro y engorroso. La otra cuestión a discutir es, cuál es el beneficio de detectar la DMG cuando el tratamiento de la misma con dieta e insulina demostraron reducir las macrosomías pero no el número de cesáreas ni traumas del parto².

Por último, habría que confirmar con estudios locales la validez externa* de este estudio, sobre todo teniendo en cuenta el tipo de población donde uno plantea el rastreo. En este estudio, a las mujeres hispanas se las incluye en el subtipo de raza "otras", junto con mujeres asiáticas del sur (indias, pakistanies) y de los países del medio Oriente. Sin embargo la población de Argentina (principalmente la urbana) podría ser comparada mayoritariamente con la de raza blanca del estudio. La principal controversia con el rastreo de la DMG no es cómo realizarlo sino decidir si tiene sentido hacer o no el rastreo de esta entidad. La estrategia más razonable parecería ser la de realizar el rastreo selectivamente a pacientes de alto riesgo: $>30$ años, obesas, historia previa de macrosomías, malformaciones o abortos y antecedentes de DMG.

*Ver Glosario

Dr. Miguel A. Zárate Unidad de Medicina Familiar y Preventiva. Hospital Italiano de Buenos Aires. 